\title{
Cristina Diamant
}

\section{Stranger(s') Voices at Home: The Many faces of Cillian Murphy as the Misfit}

Abstract: Independent Ireland, slowly shedding the "Church and State" image of perfect unity rooted in indigenous culture, seems to offer little hope for a sense of self-coherence to the Irish young man. Three instances of marginality as embodied by Cillian Murphy in Disco Pigs (2001), Intermission (2003), and Breakfast on Pluto (2005) examine and explore the unnecessary misadventures of youth dangerously veering towards an extra-systemic position. They are shaped by their erotic encounters that lay bare their raw, unhinged nature and desire to be acknowledged as different, yet human. Walking the line between comedy and drama, there is less genre-specific pressure to fit the narrative into certain patterns and more room to explore the clashing codes these peripheral characters work with, trying to make sense of their experience and their place in the world.

Keywords: Irish Literature; Cillian Murphy; Difference; Discourse; Marginal; Politics; Self-image.

\section{Cristina Diamant}

Babeș-Bolyai University, Cluj-Napoca, Romania cristina.c.diamant@gmail.com

DOI: 10.24193/cechinox.2017.32.25
I don't think you care either way, my good-looking friend. ${ }^{1}$

Oillian Murphy, speaking to The Movie Show in 2006 of his character in Breakfast on Pluto, said that what sets "Kitten" apart from other portrayals of transvestites is that (s)he does not come with an "off" button, thus always being "in character," so to speak, and following a kind of solipsistic logic. This paper sets out to discuss the way in which the three misfit anti-heroes of Disco Pigs (2001), Intermission (2003), and Breakfast on Pluto (2005) played by Cillian Murphy come without an "off" button, being unable to fake being "one of us" in daily life and especially in their love life. Their very strangeness fuels in part the comedy, though we are not meant to forget that tendentious humour involves another's taking the position of the victim/ target. Characters driven by the Lacanian lacking defined as desire, they bring to the forefront a new portrayal of the young Irish man. Caught between conflicting attitudes, namely being "[d]istrustful of the hippy past, dismayed by the yuppie present, disillusioned with a bumpy future," ${ }^{2}$ these characters cannot be found lacking irony. The comic shine given to 
their struggles, however, keeps the audience at an arm's length and does not allow us to empathize with them although we are given an approximated understanding of their highly personal logic.

The role of one's love life in constructing identity is not presented in the almost cookie-cutter manner of romantic comedies, but provides the viewer with an idiosyncratic sensibility. The "classic" type of imagery associated by Northrop Frye with the mythos of romance, namely "spring, dawn, order, fertility, vigour and youth" [italics mine] are immediately apparent in the vibrant colour scheme and visibly constructed symmetry of Disco Pigs and the flamboyancy of Breakfast on Pluto - both narratives starting with a retrospective view. Intermission is the bleaker of the three and also, incidentally, the one presented "in real time," not reconstructed through a lingering view of one's coming of age. Indeed, the three films go beyond the common discourse about love and explore the tensions between love and sexuality as seen by these characters on the fringes of society. In a sense, these are very "Irish" in character, focusing on the destructive nature rather than on offering a Hollywoodian "happily ever after". Even though John and Deirdre are brought back together, Intermission still ends on a bittersweet note by cutting to Sam and his wife, as a warning against the fickleness of all relationships and juxtaposing a "true" making-up with a resentful one. As such, Pat Murphy is right in assessing that love stories coming out of Ireland have a marked preference for "gloomy and thwarted and tragic," ${ }^{4}$ maintaining a certain level of punishment. As a sidenote, while O'Connell speaks of the general assumption that Ireland has an affinity for the literary rather than the visual, let us keep in mind that both Disco Pigs and Breakfast on Pluto are adaptations from literary sources.

Tales of urban life, the three movies skillfully combine similarity and difference in their take on the romantic comedy hero, lending him sufficient humanity to be familiar, but disruptive enough to surprise viewers and betray their expectations with their twists. In the words of the sociologist Anthony Giddens, these characters establish their own ontological order of the self so as to reduce the risk of meaninglessness. What is particular, however, is that not many share their ontological order, leaving them on the fringes of society, marginal and confused. The touch of existentialism to these anti-heroes's progress is motivated by Cillian Murphy's fascination with "transformative roles [...] that I think are the most appealing, really, where you get to travel a huge distance from who you are as a person. ${ }^{5}$ Gender roles are subverted, not only in the obvious sense in Breakfast on Pluto, but also in the conflicting sensibilities of Pig and John. Since Irish cinema, much like literature, has moved from a discourse that grounds nationality to a sort of darker cosmopolitanism, these films, too, touch upon darker aspects of humanity, from the self-alienation, domestic abuse, and physical violence of Disco Pigs to the moral ambiguity of Intermission. Murphy appreciates the fact that "the darker stuff has greater potential for drama" as well as the mixture of genres, highlighting that in Intermission (though this could be said of all three) "[i]t's not comedy for comedy's sake - it's informed by something else. I

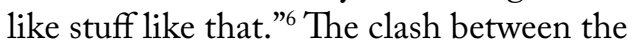
hopes and dreams of these characters and 
society's expectations is comic because the heroes seem blissfully unaware of them or, at most, indifferent to them, constructing their own heterologies, as their disturbances have no place in the given system of visible coordinates creating the sensible framework of meanings. As Zygmunt Bauman would put it, these indeterminate characters, although free to choose their identity in a modern setting, seem to be working against this very freedom, "closing in" their own worlds. Their shared beliefs seem to be of a circular, maddening logic of the "I am because I am that which I am" type, from which derives a "We are because I love that which we are." Given the Catholic background, three traditional chief Christian values inform this discourse. Love assumes central position because it embraces difference rather than just tolerate it as hope does. Faith is pushed on the last place, most evidently in Breakfast on Pluto, because it feeds on a necessary shared assumption of non-difference.

The violence of these movies is made no less disturbing by its nihilism, especially in the gratuitous attacks of Disco Pigs. Despite what we see, the characters tend to speak of their worlds in fairy-tale terms as a psychological defence against the brutality of what is going on. While Pig and Runt share a "King and Queen" fantasy, John believes that Deirdre will be able to tell that this five to six weeks "intermission" is nothing but a test of her love she is supposed to heroically pass, while "Saint" Kitten's optimism seems otherworldly. The fairy-tale logic of the "meant to be" works to justify the violence in these stories, from Pig viciously killing the boy Runt danced with "just for the try" to John planning Deirdre and Sam's kidnapping. The director of
Breakfast on Pluto, when defending himself against the feminist critique on The Crying Game, asserted that, sometimes, characters may be able to escape the hierarchical power ordering of (female) victim and (male) aggressor, highlighting what he calls the "emancipatory power of an individual choice" 7 . While the violence of these men is not seen as endearing (the American perspective) or as self-destructive, a momentary slippance from the status quo (the British perspective), it is pivotal in creating the image of the anti-hero.

If Breakfast on Pluto is, according to Murphy, a triumph of innocence, I would like to argue that Disco Pigs, despite its homicidal end, is a tragic preserving of Pig's innocence at the hands of the more perceptive Runt. What she does is, in a way, separate his fairy-tale like vision from the contamination of the real world he seems unable to grasp. ${ }^{8}$ Their story was one of gradual, but inevitable separation as they started to develop in a different pace, driven by "the need to negotiate re-entry (Runt) or permanent exit (Pig) from the conventional world that shapes the narrative path of this film." ${ }^{9}$ Linguistically separated from the rest of the world, as the liquor store scene suggests, they define a new symbolic order of the baby-talk type which feeds on repetition, as well as the black and white "us or them" logic of fairy tales. As such, "it's kinda hard to talk about the characters separate because they're so close together, you know, you have to talk about the two together" 10 , inhabiting the same symbolic space and "feeding" upon each other. Pig's co-dependency issues start to aggravate as this ontological order starts collapsing once he discovers his attraction towards Runt and she discovers 
female companionship, starting to look in a different direction. If, until then, they had always looked in the same direction, Pig starts looking at her adoringly while she looks "for something new." In a sense, Disco Pigs has reversed the gender dynamic as it is Runt who sets the two free, giving up on Pig, who was "my whole life, him. My only one. He da best!... and worst, pal in dis bad old world." 11

Intermission, too, presents a character with a psychological and social difference. John is surprisingly out of touch with the conventions of real life interaction and turns absolutely ridiculous when, 6 weeks later, he breaks into Deirdre's house comically searching for the "baldy cunt" in the closet with chaser scene music in the background although he was the one to ask for a break. When the kidnapping scene begins, we first see at 1:10:00 the hand of the "the really dangerous fuck of the trio" knock, then a blurred close-up of their faces through the glass, from the shortest to the tallest. The man in the middle moves on the spot as if anxious, but when we hear her take hold of the handle, we see the masked figure to the right (which we later infer that it is John) suddenly turn to the side, as if not to face her, then quickly revert to the aggressive stance. The frontal shot from her point of view once the door opens moves to an extreme close-up of his eyes through the mask in a shaky move, followed by a close-up of her confused face taking a half-step back out of instinctive self-defence. His fixation with Deirdre is thus given away by little gestures adding up. When writing on Sam's back "DON'T BE NASTY MAN," he feels the need for reassurance (and writes "BE GOOD") as he is well aware that there was no empty boasting in the stranger's warning - he is, as the viewer knows from the opening sequence, a wild card. When he returns, we are made to empathize with Deirdre as she peeks in (as indicated by the shaky medium shot of them including the side of her head). Instead of answering his increasingly agitated accomplice's questions, he admonishes his accomplice for "not being good," breaking character and his cover in the process. When the other kidnapper asks John to clarify things, he is still too concerned with her to break the gaze, so the punch gets him entirely by surprise. Rubbing his head in disbelief, he retorts verbally by writing "YOU PRICK." Once he is shot, she runs off to see if he is alright although he was the one to come up the plan. Her almost fairy-tale reaction makes the viewer believe these two are "meant to be" despite their differences and, once they get back together, John also seems to earn the approval of the community in the centre of which he returns in the final pub scene.

Breakfast on Pluto, while presenting another character that is a misfit in society, also speaks of sexual difference. This is the story of a miss/ mister obsessed with the mother's mystery and repeatedly trying to construct a coherent narrative of the self. The upbeat music of the opening, leaving audible only the first few lines, namely "Sugar baby love, I didn't mean to make you blue," can be seen not only as contrasting with the mundane depicted, but also as a foreshadowing. "Sugar," even saccharine "baby" Kitten is made "blue," for example, when the magician mocks "Patricia" who admitted to be looking for his/ her mother, forcing him/ her to embrace the speaker box and fall back into childlike crying. 
Cillian Murphy, too, feels that this is her theme song. The over-the-shoulder view, followed by an aerial view of his/her androgynous figure in the opening plays with the viewers' expectations, as it is only when speaking that they realize that Kitten is Patrick. The reverse may be said to be true once we are given an overview of his/her school years. The protagonist may look like Patrick, but the speech gives him away as Kitten. The perspective adopted is given away by the very telling first few lines: "Not many people can take the tale of Patrick Braden aka Saint Kitten, who strutted the catwalks face lit by a halo of flashbulbs as 'Oh!' she shrieked: 'I told you, from my best side, darlings' "12 [italics mine]. The swaying moves indicated by the shoulders, combined with Kitten's looking away to an audience unknown reinforced the theatrical character of the scene, the apparent role-playing. When meeting the very inquisitive half-brother, Kitten, who has, until now, looked defensively at the ground, is now still visibly shaken and slightly trembling. Contrary to what Kitten expected, the brother thinks she's "nice." When reunited briefly in the end, (s)he presents him/herself as "Phantom Lady," the name previously given to the absent mother in absence, as a tacit way of acknowledging that (s)he has made peace with his/her painful past. The past is kept at a distance through the aesthetic approach to it, and when Kitten, with a tired look, vacantly gazing into the mirror and swinging on the mock-Romantic swing adorned with flowers, tells the unseen client that "Oh, I'm not a boy, sir. [...] Yes. You can call me Patricia"13, this is not unlike the "Call me Ishmael" of Mobby Dick. Cillian Murphy, a self-proclaimed fan of the original novel, has tried his best "to achieve a femininity as opposed to being effeminate" believing "there's a difference because one is an affectation and the other is just the way somebody is and the whole transvestitism, and wearing women's clothes and all that is very peripherical to the character"14. This very humane portrait of "Saint" Kitten allows the viewer to overlook the extravagance on-screen and sympathize with the character's need for fairy-tale like logic, reinforced time and time again by the presence of the robins. Although Kitten goes through very trying circumstances, the director "has been at pains to stress that this is not a film about politics but rather addresses the question of how an individual can preserve his own identity when powerful competing ideologies seek to win followers" ${ }^{15}$. What Kitten does is mimic the undying optimism of Voltaire's Candide. Cillian Murphy's acting is not stereotypical, but highly understanding and sympathetic of a troubled outcast, as he admits to not feeling as if he played a transvestite, but "you know, you're just playing the character and these things are aspects of the characters ${ }^{16}$ and "that character is never trying to convince people that she is a she. It's just the way she is." 17

The director's disclaimer does nothing to hide that Breakfast on Pluto is, even more obviously than the other two, pleading for the legitimacy of a-political discourse in a political or, if Baudrillard is to be believed, transpolitical world. The backdrop to Kitten's misadventures are the tumultuous 1970s and it is her perspective that pushes the recurring subtext out of sight and out of mind. The identity Kitten rejects is double: "Paddy" is not just an endearing nickname for "Patrick," her Christian name, but also an offensive English term for the Irish. In 
London, ready to meet "the Phantom Lady," Kitten wishes to cover herself in images of acknowledged hegemony when dolling herself up using a picture of Mitzi Gaynor as reference: "I want... English. I want conservative. [...] I want powerful," she tells her co-worker at the peep show, expecting feedback. To fit in the lost mother's new world, there is no room for the usual flamboyancy and playful rejection of the "serious, serious, serious": Kitten tries to make herself into the image of the approximated image of a never-before-seen image. Through these parallel mirrors of accepted codes, the disguise erases identity out of a desire to be accepted. Patrick was used to rejection and the incentive to finally leave the bitter Braden household is given by the sister's rejection of a reconciliatory hug, denying his humanity by calling him "you creature!" Giving up on the previous compromise, the hero(ine) shrugs it off, rhetorically asking "Oh, what's the point?" before getting up to leave, as it is later revealed, forever. Chapter 6, when Patrick writes a fictional account of the meeting of the parents, is provocatively titled "In Which I Am Mis-Conceived." Patrick came into this world "the wrong way" as a child of sin, later abandoned by the mother in a basket with blue clothes on. Another way in which (s)he violates norms is how strongly (s)he opposes the "serious," normative order, much preferring a dialogical, carnivalesque mixture of genres and voices. Seriousness is dismissed even from play: when the childhood friends just as marginal as her/himself, Charlie (the girl of African descent), Laurence (suffering from Down's syndrome), and Irwin (anxious and submissive) imitate the adults, crying out "For Ireland!," he forces his way out of their game by "killing" himself. It is also worth noting that the only adult figure who seems to accept Patrick for his inner Kitten is the father of the marginal Laurence who also first mentions the mother's real name and her resemblance to Mitzi Gaynor. When discussing with Charlie the move to London, Kitten complains about the omnipresence of the word "serious," eroding this bubble (s)he's building. Patrick's Creative Writing teacher, prompting the class to write a free-form essay, singles out Patrick with a mocking gaze when suggesting as a possible topic "I was Dracula's girlfriend." This is no accident in the economy of the narrative. All the topics suggested allude to variations of Irishness: Dracula's author was Irish yet explored other landscapes, "I fought in the Easter Rising" hints at Irish nationalism, while "A day in the life of a noble" seems tame, yet it is just as politically charged with Anglo-Irish conflicts and vital for an understanding of the national psyche. The implication here is also that Patrick is "not Irish enough" because of his interests for romances cut out of the framework of reality. Rather than fight the assumption, Patrick dwells in it and uses the trope to subvert it. The demonic and sensual being inhabits the very body of one of God's devout, rendering the beautiful innocent impossible to save. To his mind's eye, Father Liam takes flight much like a vampire and the story's merit is that it speaks of "girls in mortal danger." Jonathan Bolton points out that Patrick, from his view on the margin, also notices the only accepted social re-absorption of femininity in priesthood, where the images of frocks and dresses blend together. Everything is to be playfully re-invested with meanings.

Around this time, giving up on Physical Education for Home Economics, 
Patrick discovers a taste for "glamour," for outlandish and seemingly magical extravagance that rejects the hegemonic order. Indeed, Kitten's two romances are with individuals who make a living out of selling illusions, from Billy the rockstar to Bertie the magician. Even so, the political is pervasive in the 1970s' Ireland. Billy's band, The Mohawks, is a wafer-thin allusion to the right of the natives to fight back, using immediately recognisable and seemingly harmless (because devoid of meaning) pop culture iconicity. Indigenous Irish cultural identity cannot be safely discussed out in the open, so it threats to overflow all the other spaces in an obsessive frenzy. Despite all the (sub)cultural imports, a fixation with stasis remains, and Kitten's heterogeneity of alien culture is shown to be potentially liberating, although mainly escapist and ultimately disposable. High camp only makes the "seriousness" of militant nationalism all the more ridiculous in this juxtaposition. While the music is feel-good glam rockabilly, Billy directly prompts Kitten in the van on their first meeting, asking for an opinion on "this trouble in the North" before showing his true colours and involvement with the IRA. The immediacy of the question is an oblique rendition of the "friend or foe?" identity-check at any border. To side with the British would be the official version, but that is no safer in the context than to side with the terrorists to protect one's projection of national identity. Kitten vainly tries to give an answer that indicates no political commitment, discussing it as a threat to the existing order, something "serious." Her position on the matter is actually truly democratic, picturing the place of Power as structurally empty, no one having a "natural" claim to it, neither the native, nor the "civilising" British. As it happens in all conflicts, however, the world is brutally divided and this third option is seen as dangerous fence-walking. For a while, she uses glamour to cover up, hand-sewing a "squaw" costume to join their shows. Ironically, they flirt on stage during a performance given as a political benefit concert at a Republican Welfare Association, a clash of codes in itself. Her image makes her into another target for social violence and the band is booed off the stage. According to Patrick Mullen, Kitten is able to circulate and critique several forms of expression and alienation because of her very own production of self-image; she has produced herself into "a complex interplay of multiple images and does not conform or contain herself into any purified or rigidly authentic expression." ${ }^{18}$ Later, at the London nightclub, Kitten finds it impossible to connect with the stranger eager to discuss "fuckin' Ulster." Rejected previously by another one and called "a bloke," Kitten is apprehensive when offered a drink and needs re-assurance that her identity is not misread, asking, after a pause, if he is sure he wishes to buy her one. Her ignorance of the political is foregrounded when mistaking the lively audience for "football supporters" when in fact, as her British partner ironically puts it, they are all returned "royal engineers" or soldiers. The possibility for the presence of an Irish-born cross-dresser in a club frequented by British soldiers to be devoid of any political agenda is entirely dismissed by both press and police once an IRA-planted bomb destroys the place. Forced once again into a "serious" narrative and chastised for being "a Paddy," Kitten manages to prove her innocence only with another 
fictional account of her life, this time as a "transvestite terrorist." The "weapon" in this mock-narrative is her perfume, the item that saved her when her first client attempted to choke her. Then, as well, Kitten was uncomfortable with being treated as lesser-than. Asked to disrobe, she playfully questioned the client's taste in her clothes, but he was having none of it, framing it as an order ending approvingly in "that's a good lad." Economics dictated that, for the time being, he owned her and so he could try to dispose of her, as well, not having to treat Kitten as a fellow human. Kitten's leitmotif becomes, naturally, the question that verifies her status as worth treating as more than an object: suppose she were fallen on a floor, would anyone take her to the hospital? After all, she once even narrowly escapes death because she is deemed not worth the bullet, prompting her to wonder what is about "nancy boys" that makes them completely extra-systemic. In the interrogation room, noticing the policeman's barely-restrained disgust, Kitten plays on it to subvert the hunter-hunted dynamic by chasing him around the room. Once the policemen realise her victimhood, she begs to be kept in the prison where she feels more secure than outside, pleading to be "the best prisoner" and even unsuccessfully trying to run back. After all, society had proven, time and time again, that it cannot accept those who reject its framework.

However much Kitten refuses to speak of anything "serious," politics repeatedly invades her life. Billy hides guns for the IRA, Irwin also tries to collaborate with them although he is woefully unprepared for the scale of the events and gets killed in the process, while Laurence is blown apart by an IRA bomb he mistakes for a
Dalek from his Dr Who childhood. Irwin, swallowing up the revolutionary dream, is crudely reprimanded by his superiors when he wets himself during the first assassination he unwillingly witnesses and is asked what else he expected. His attempt to escape the IRA is futile at this point and, while one of his superiors refuses to eliminate him on the grounds of kinship, one of the chief Irish values, since he went to school with Irwin's brother and feels partly connected to him, the other has no qualms in shooting him point-blank. Chapter 19 of Kitten's story, titled "In Which I Leave that Strife-torn Little Hamlet," alludes to the selection operated in the sensible. Patrick seems more fed up with the provincialism, small-mindedness, and lack of opportunity than with the political and even armed conflicts at the Northern border. "Strife-torn" is revealed, then, to be an umbrella term for both the political unrest that swallows his friends and for the real lack of kinship and love in the community. Fervently identifying itself with Catholicism, the community sets Father Liam's parish on fire on Christmas Eve to purge the place of two "abominations" hiding there: Charlie, an unwed mother, and her transgender friend. No more belief in the redeeming possibility of faith or hope is possible. Love is what saves the two, as evidenced by Charlie making up her mind at the abortion clinic to keep the baby after Kitten half-jokingly warns her that it might turn out to be a "freak" like her.

Melodrama is a learned idiolect for Kitten, a self-aware mode of expression that hides a disbelief in the possibility of truth. Everything is a story with an elusive origin that may not be retrieved, not just the Phantom Lady. Talking in an affected 
manner is (sub)cultural rather than natural, learned by imitating movie starts while playing out an interaction with the characters on TV. The line between life and illusion is willingly obscured to deny life its ominous power. In the novel, the narrator even has Patrick "Pussy" Braden think that the only way to "negotiate the mindfields of this world" is "through pastiche, wickedness and cheek" ${ }^{19}$. It is in one of the languages of Patrick/Kitten, that of fairy tale echoes, telling "a story that addresses the problems of desire and repression, violation and violence, guilt and redemption, that each of the characters must work through," ${ }^{20}$ that Father Liam starts his confession about the missing mother in the peepshow booth. Moreover, the chapter division and self-explanatory titles, reminiscent of the Victorian novel tradition, suggest the narratorial voice's hope in a redemption arc. This is partly successful as, unlike the novel, the overall retrospective view is that of Kitten narrating to Charlie's infant, not writing her life story in a psychiatric ward. However, in both versions the outsider is adamant to stand corrected, as seen during one of the peepshows, when a singing "Patricia" is corrected by a client - not "waggely," but "waggedy" and she retorts bitterly while mocking the small price that gave the client the illusion that he has power over her. Later singing the same song with Charlie, she voices her own uncertainty and gladly accepts "waggedy" as the canon once Father Liam states that this is how the lost mother used to sing it. The suggestion to change must never come from those momentarily in power. Kitten is extremely sensitive to the hierarchy established by economics, as seen in the dialogue with her half-brother, also called Patrick. When, quite in disbelief, the little boy says that everyone has a phone, Kitten is quick to add that all possessions are a matter of what you can afford. During their second encounter, she calls him not without a certain resentment the boy from the "multi-telephone household," painfully aware that he enjoys all that was denied to her. If Kitten dislikes being corrected and either snaps or jeers, young Patrick readily accepts that saying "a bun in the fireplace" was a misuse of the idiom and easily shrugs it off. Those denied power are doomed to be obsessed with it even while denying it and their inferiority complex, it would seem, while those enjoying a higher status have no reason to feel their image so easily threatened. On the other hand, Kitten's image is all she has and the inability "to apply oneself" is a misguided assumption. Paradoxically, the only thing Kitten takes seriously is the rejection of the "serious," so much that she violently snaps when Billy calls her "Patrick." Pig, as well, proved to be unable to stop "playing" outside the system and accept the hegemonic order, while John is never "serious" enough about love or companionship.

Seen as a more "actorly' counterpart to Colin Farrel [who] has been largely trapped in pretty boy lead roles since his turn in Joel Schumacher's Tigerland,"21 Cillian Murphy faces, however, the danger of "being typecast in on-the-edge psycho roles." 22 Even so, he plays these with remarkable understanding for the heart of darkness hidden within humanity. If, following Stanislavsky, the Stoics are right and with simple, few tools one can achieve perfection by absolutely mastering the simplest technique and, consequently, the difficult becomes easy and the easy 
habitual, so that the habitual may become beautiful, Cillian Murphy's portrayal of solipsistic marginal identities may be one of the keys in making the apparent mundane Irish life become worth the screentime. Since, according to O'Connel, "in post-ceasefire Ireland it could be argued that the traditional man has no future," ${ }^{23}$ the very presence of the confused man of the Now Cillian Murphy is justified. Although he credits the scripts for all his accomplishments, he admits that, as an actor, his only goal is spreading the message of acceptance. Not surprisingly, then, voicing marginal characters is a step in this direction. His concern with authenticity, mirrored by his roles as a self-questioning anti-hero, also becomes apparent when, in an interview about Breakfast on Pluto, he says of the very medium of interviews in general to be "a very weird environment, isn't it? It's completely false, but I wanted it for this film because I believe in it so much and I believe in the movie, in the story that it wants to tell." ${ }^{24}$ While Disco Pigs explores larger youth issues in the context of a society that proves to be unable to accommodate non-conformity and deal with social disadvantage, Intermission is an "unnecessary journey" as well as "a very sharp insight into Irish men who can't just say the thing and do it - they have to go and do all the most ridiculous things to get to the actual point, ${ }^{25}$ with Breakfast on Pluto showcasing the dangers of the close-minded old-fashioned narrative of "the Church and the State" that cannot accept the ambiguity embodied by "Saint" Kitten. What they all strive to do, with varying success, is, as Chris Colfer puts it in Struck by Lighting: The Carson Philips Journal, to show the world who they are before they are told.

\section{BibLIOGRAPHY}

Barton, Ruth, Irish National Cinema, London \& New York, Routledge, 2004

Bolton, Jonathan, Blighted Beginnings. Coming of Age in Independent Ireland, Lewisburg, Bucknell University Press, 2010. Web. As found on: https://books.google.ro/books?id=K0jTV skpnMC\&printsec $=$ frontcover $\# v=$ onepage\&q $\& f=$ false

Flynn, Roderick and Patrick Brereton, Historical Dictionary of Irish Cinema, Lanham, The Scarecrow Press, 2007

Mullen, Patrick R., The Poor Bugger's Tool. Irish Modernism, Queer Labor, and Postcolonial History, Oxford, Oxford University Press, 2012. Web. As found on: https://books.google.ro/books?id=FW37GJ7Dc$\mathrm{CkC} \&$ printsec $=$ frontcover\&source $=$ gbs_ge_summary_r\&cad $=0 \# \mathrm{v}=$ onepage \&q\&f=false

O'Brien, Harvey, The Identity of an Irish Cinema, 3rd edition, 2007

O'Connell, Diog, New Irish Story-Tellers. Narrative Strategies in Film, Bristol \& Chicago, Intellect, 2010 Rancière, Jacques. The Politics of Aesthetics. The Distribution of the Sensible, translated with and introduction by Gabriel Rockhill, 2nd edition, 6th reprinting, New York, Continuum, 2011

Ryan, Matthew, Ourselves Alone: Solipsism in Neil Jordan's Novels and Films, Monash University.

\section{VIDEOS:}

Interview on Breakfast on Pluto with Cillian Murphy, as found on: https://www.youtube.com/ watch?v=zLgGQ-rcghQ

Interview on Disco Pigs with Elaine Cassidy at Berlin, 2001, as found on: https://www.youtube.com/ watch?v=9AtE4C309P8 
Interview with Cillian Murphy on Disco Pigs at Berlin, 2001, as found on: https://www.youtube.com/ watch?v=86ZVjZEN5uw

Interview with Cillian Murphy on Intermission, as found on: http://www.bbc.co.uk/films/2003/11/25/ cillian_murphy_intermission_interview.shtml

Interview with Cillian Murphy, as found on: http://www.blackfilm.com/20051111/features/cilliammurphy.shtml

The Movie Show interview with Cillian Murphy, as found on: https://www.youtube.com/ watch?v=sxgiNq7Rg3I

\section{NoTeS}

1. Bill Hatchett, Breakfast on Pluto, 25:56-26:10.

2. Diog O'Connell, New Irish Story-Tellers. Narrative Strategies in Film, Bristol \& Chicago, Intellect, 2010, p. 63.

3. Northrop Frye, Anatomy of Criticism, London, Penguin, 1957, p. 187-8, qtd. in O'Connell, p. 82.

4. Niamh Thornton, "Interview with Pat Murphy," Film \& Film Culture, 2004, Vol. 1, 10, qtd. in O'Connell, p. 118.

5. Breakfast on Pluto, 0:37-0:46, https://www.youtube.com/watch?v=zLgGQ-rcghQ.

6. http://www.bbc.co.uk/films/2003/11/25/cillian_murphy_intermission_interview.shtml.

7. Matthew Ryan, Ourselves Alone: Solipsism in Neil Jordan's Novels and Films, Monash University, p. 190.

8. "Pig is a bit more mad than she is but he never gets to express that because she's always there to bring him back to kind of reality in a way. She's also a lot deeper than him, like more in touch with her feelings, [...] she's just kinda more spiritual than he is and he can't understand that and, you know, she finds that funny, the fact that he's, that everything's just kind of black and white" [italics mine], 0:44 -1:11, https://www.youtube.com/watch?v=9AtE4C309P8.

9. O'Connell, p. 55.

10. 1:11-1:18, https://www.youtube.com/watch?v=9AtE4C309P8.

11. Disco Pigs, 32:14.

12. Breakfast on Pluto, 1:30-1:44.

13. Breakfast on Pluto, 1:34:38 - 1:34:46.

14. 0:55-1:11, https://www.youtube.com/watch?v=zLgGQ-rcghQ.

15. Roderick Flynn and Patrick Brereton, Historical Dictionary of Irish Cinema, Lanham, The Scarecrow Press, 2007, p. 72.

16. Breakfast on Pluto, 3:12-3:22, https://www.youtube.com/watch?v=zLgGQ-rcghQ.

17. http://www.blackfilm.com/20051111/features/cilliammurphy.shtml.

18. Mullen, p. 143.

19. Patrick McCabe, Breakfast on Pluto, New York, Harper Collins, 1998, xiii, as quoted in Bolton, p. 168.

20. Mullen, p. 144.

21. Flynn, p. 260.

22. Ibidem.

23. O'Connell, p. 82.

24. Breakfast on Pluto, 3:16- 3:32, https://www.youtube.com/watch?v=zLgGQ-rcghQ.

25. http://www.bbc.co.uk/films/2003/11/25/cillian_murphy_intermission_interview.shtml. 